\title{
O imperativo gramatical no português brasileiro*
}

\author{
The imperative form in Brazilian Portuguese
}

\section{Daisy Barbara Borges Cardoso \\ UnB}

\begin{abstract}
This paper intends to describe and analyze the variable use of the imperative mood in the Brazilian Portuguese and its correlation with the syntax of negation. We will also discuss the historical and syntactical aspects subjacent to the variation of the phenomenon. This variation happens in relation to the prevision of the traditional grammar, which, in the context of the explicit pronoun you, foresees the use of verbal forms associated to the subjunctive for the grammatical imperative in the negative and affirmative forms. The presented data on spoken and written language exemplify the strategies of negation in the Brazilian Portuguese and its relation with the use of the grammatical imperative. After the analysis of the data and presented facts, two hypotheses are stated: i. mitigation of the speech acts in order to justify an increase in the use of a true imperative in postverbal negation and double negation structures; ii. gradual weakening/loss of the imperative morphology in the Brazilian Portuguese in order to justify the negation of the true imperative.
\end{abstract}

\section{Keywords}

Imperative mood, variation, strategies of negation.

\section{Resumo}

Este artigo pretende descrever e analisar o uso variável do imperativo gramatical no português brasileiro e sua correlação com a sintaxe de 
negação. Discutiremos também aspectos históricos e morfossintáticos subjacentes à variação do fenômeno. Essa variação se dá em relação à previsão da gramática tradicional que, em contexto de pronome você explícito, prevê o uso de formas verbais associadas ao subjuntivo para o imperativo gramatical afirmativo e negativo. Os dados apresentados de língua falada e escrita ilustram as estratégias de negação no português brasileiro e sua relação com o uso do imperativo gramatical. Após a análise dos dados e dos fatos apresentados, levantam-se duas hipóteses: i. mitigação dos atos de fala, para justificar o aumento do uso de imperativo verdadeiro em estruturas com negação pós-verbal e dupla negação; ii. enfraquecimento/perda gradual da morfologia imperativa no português brasileiro, para justificar a negação do imperativo verdadeiro.

\section{Palavras-chave}

Modo imperativo, variação, estratégias de negação. 


\section{INTRODUÇÃO}

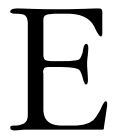

ste estudo examina o imperativo gramatical no português brasileiro (PB), discutindo aspectos como o uso variável das formas do imperativo verdadeiro e do imperativo surrogate (substituto ou supletivo) e sua correlação com a sintaxe da negação. O texto está organizado em quatro seções. Na primeira, discute-se a caracterização do modo imperativo gramatical como ato diretivo, assim como a nomenclatura utilizada por lingüistas e autores da tradição gramatical. Em seguida, é apresentado um breve panorama de pesquisas variacionistas desenvolvidas no Brasil acerca da variação do imperativo gramatical. Na seção 3, são abordados fatores históricos e morfossintáticos subjacentes ao fenômeno variável. A última seção traz uma abordagem da relação entre a posição da negação nas sentenças e o fato de o português brasileiro negar o imperativo verdadeiro. As considerações finais trazem uma reflexão sobre o estatuto do verbo no modo imperativo e sua correlação com a sintaxe da negação.

\section{O ATO DE FALA DIRETIVO E A EXPRESSÃO GRAMATICAL DO IMPERATIVO}

\subsection{O ato de fala diretivo}

Os atos de fala são atos ilocutórios ${ }^{1}$ que se caracterizam por conter um objetivo e uma força ilocutória que pode ser suavizada ou não em função da intenção comunicativa dos interlocutores (cf. SEARLE, 1969; MATEUS et al., 2003, p. 73-74). Dessa forma, o ato diretivo, uma das categorias dos atos de fala, é aquele que visa obter do alocutário o reconhecimento do que foi expresso pelo locutor, e este espera obter um comportamento determinado do seu interlocutor, imprimindo força ilocutória de acordo com seu objetivo.

$\mathrm{O}$ ato diretivo pode ser realizado por meio de ordem, pedido, sugestão, convite e conselho (cf. CUNHA \& CINTRA, 1985), os quais, por sua vez, 
podem ser expressos por meio das formas variantes do imperativo gramatical, como ilustrado em (1), ou ainda por meio de frase nominal, com tempos do indicativo, com o infinitivo, gerúndio, com frases interrogativas, como ilustram os exemplos de (2) a (6).

(1) Saia daqui! / Sai daqui!

(2) Silêncio!

(3) Agora você faz uma garrucha ...

(4) Não fumar.

(5) Andando!

(6) Poderia servir o jantar?

Segundo Mateus et al. (2003), existe um significado pragmático subjacente a cada um desses atos, cabendo aos interlocutores a distinção entre intenção de ordem mais rude de outra mais amena. De acordo com Cunha \& Cintra (1985), a língua dispõe de recursos para o falante se expressar, conforme sua intenção comunicativa, seja reforçando o pedido ou ordem por meio de repetições, advérbios, como exemplificado em (7) e (8), seja atenuando o pedido, como em (9), por meio de fórmulas de polidez.

(7) Saia, saia daqui.

(8) Fale rápido.

(9) O senhor me desculpe, por favor.

O imperativo gramatical é, portanto, um ato diretivo, cuja realização está associada a fatores de natureza pragmática e discursiva, bem como a processos morfossintáticos que determinam as propriedades de suas formas gramaticais e sua distribuição na estrutura oracional, como será demonstrado no decorrer do presente estudo.

\subsection{A expressão gramatical do imperativo}

Segundo Mateus et al. (2003, p. 254), do ponto de vista pragmático, o imperativo está ligado à modalidade deôntica, aquela relacionada "às 
circunstâncias externas (pessoais, regras sociais ou normas) que permitem ou obrigam o participante a envolver-se na situação." São consideradas gramaticalmente imperativas as frases que expressam ato ilocutório diretivo, apresentando características formais do modo imperativo e valores como ordem, pedido, conselho, instrução. Dessa forma, esses valores semânticos podem ser realizados por meio de diferentes formas verbais, na forma de um ato diretivo direto ou indireto, conforme foi ilustrado nos exemplos de (1) a (9).

Considerando-se uma abordagem morfossintática, o imperativo no português europeu é descrito pelas autoras como um modo que apresenta formas verbais próprias só para as segundas pessoas do singular $(t u)$ e do plural (vós) do imperativo afirmativo. As demais pessoas do afirmativo, bem como as pessoas do imperativo negativo, são supridas por formas supletivas, valendo-se das formas verbais do subjuntivo ou de outras formas como o indicativo, o infinitivo ou o gerúndio.

Rivero (1994) e Rivero \& Terzi (1995) usam o termo imperativo verdadeiro para referir-se à forma verbal própria, morfologicamente marcada para o imperativo e usada para a segunda pessoa do discurso (singular e plural) e imperativo surrogate para referir-se às formas substitutas ou supletivas, aquelas que se referem às demais pessoas do imperativo afirmativo e a todas as pessoas do imperativo negativo, podendo ser realizadas pelo indicativo, subjuntivo, infinitivo. Entre as línguas que têm imperativo marcado morfologicamente, as autoras distinguem aquelas que não negam o imperativo verdadeiro - como o espanhol castelhano -, denominadas línguas de classe I; e aquelas que negam o imperativo verdadeiro - como o búlgaro e o servocroata-, denominadas línguas de classe II. ${ }^{2}$

Para o português brasileiro, a tradição gramatical considera que o modo imperativo é formado por meio de um processo de derivação. De acordo com Bechara (1999, p. 237), as segundas pessoas desse modo verbal são derivadas das segundas pessoas do modo indicativo, sem o-s, e as demais pessoas são derivadas do modo subjuntivo. Cunha \& Cintra (1985, p. 465) não fazem referência a esse processo de derivação e afirmam que o imperativo afirmativo possui formas próprias para as segundas pessoas, sendo que as demais pessoas e o imperativo negativo são formados pelo presente do subjuntivo.

Nesse sentido, constata-se que a caracterização de Cunha \& Cintra (op. cit.) corresponde ao contraste 'imperativo verdadeiro' e 'imperativo surrogate’, formulado em Rivero (1994). Fazendo-se uma generalização, a 
gramática tradicional afirma, portanto, que o imperativo gramatical no português brasileiro codificado apresenta formas do imperativo verdadeiro para as segundas pessoas do afirmativo, ${ }^{3}$ conforme ilustra (10), e formas do imperativo surrogate para as demais pessoas do afirmativo, em (11), e para todas as pessoas do imperativo negativo, como ilustram (12) e (13).

(10) Canta tua música.

IMP AFIRM 2S (imperativo verdadeiro)

(11) Cante sua música.

IMP AFIRM 3S (imperativo surrogate)

(12) Não cantes tua música.

IMP NEG 2S (imperativo surrogate)

(13) Não cante sua música.

IMP NEG 3S (imperativo surrogate)

Devemos ressaltar que, no português brasileiro, essa correlação entre as formas pronominais e as formas verbais apresenta-se em variação no uso do imperativo falado e escrito. Para o português europeu, evidencia-se que a associação à pessoa está relacionada a julgamentos de (+-) proximidade. Ramos (1997) mostra a correlação entre o uso do tu e do você em Portugal e no Brasil. No português europeu (PE), o uso de pronome você se dá entre "iguais não-solidários e com interlocutores de status social inferior" e o uso de pronome $t u$ corresponde a tratamento íntimo e em expansão; no PB, essa distinção não é evidente; o uso de você está em expansão e o de $t u$, restrito a certas regiões, utilizando-se, muitas vezes, a forma verbal correspondente à $3^{\text {a }}$ pessoa do singular.

No português europeu, formas imperativas como Faz o dever e Diz a verdade são usadas em contexto de pronome $t u$ e refletem traços de (+ proximidade), enquanto formas como Faça o dever e Diga a verdade são usadas em contexto de pronome você e refletem traços de (-) proximidade. No português brasileiro, essas propriedades estão sendo investigadas com o objetivo de avaliarmos a possível presença desses traços nas diversas regiões do Brasil (cf. SCHERRE, 2006). Dessa forma, buscamos entender e explicar a diferença nas frequiências de uso do imperativo verdadeiro na região Nordeste em oposição às regiões Centro-Oeste e Sudeste. 
Para efeito de clareza, ressaltamos que, a partir desta parte do trabalho, adotaremos o termo imperativo substituto para nos referirmos ao imperativo denominado surrogate, nos termos de Rivero (1994), ou supletivo, nos termos de Matheus et al. (2003), que é o imperativo associado à forma subjuntiva.

\section{A EXPRESSÃO GRAMATICAL DO IMPERATIVO EM DIÁLOGOS DO PORTUGUÊS BRASILEIRO FALADO E ESCRITO}

Pesquisas têm comprovado que o imperativo gramatical no português brasileiro apresenta um uso variável em relação à prescrição da gramática normativa (cf. SCHERRE et al., 1998; 2000; 2005; SAMPAIO, 2001). Podemos afirmar que, em todas as regiões do Brasil, há uma tendência, em maior ou menor grau, à variação no uso das formas gramaticais que codificam esse modo verbal para o contexto discursivo do pronome você. ${ }^{4}$ Em algumas regiões, o imperativo verdadeiro é encontrado em mais de $95 \%$ das amostras de língua falada, como ocorre nas regiões Sudeste e Centro-Oeste (cf. SCHERRE, 2002); já em outras localidades do Brasil, esse percentual de uso cai para menos de 50\%, como ocorre em algumas cidades do Nordeste, especificamente Salvador e Recife, conforme revelam algumas pesquisas (SAMPAIO, 2001; ALVES, 2004; JESUS, 2005). Essa variação não ocorre somente na língua falada. Textos escritos de gêneros diversos também apresentam variação como evidenciam pesquisas de Scherre (2002), com base em dados de histórias em quadrinhos; Cardoso (2004), com textos literários do escritor goiano José J. Veiga; Mattos \& Wickert (2002), com letras de música de Chico Buarque e Abreu (2003), com textos literários do escritor baiano Jorge Amado.

Essas pesquisas têm mostrado que fatores lingüísticos e sociais favorecem o uso de uma ou outra forma do imperativo gramatical, e que o falante, geralmente, ao produzir essas frases, não faz a associação à pessoa do discurso, conforme a sistematização da gramática tradicional.

Os exemplos de (14) a (17) mostram o uso das formas do imperativo (verdadeiro e substituto) por um mesmo falante, em um mesmo contexto discursivo.

(14) Cheguei. ABRE a porta aí. (42 F $)^{5}$

(15) FIQUE do meu lado. Vamos embora comigo. (42 F) 
(16) NÃO ENTRA no mar. (42 F)

(17) NÃO ACEITE nada de estranho. (42 F)

De acordo com os pesquisadores citados, fatores lingüísticos como tipo de verbo e paradigma verbal; natureza afirmativa e negativa da frase; posição da partícula de negação; pronomes retos e posição e pessoa de clíticos interferem nos resultados. Fatores sociais também se têm mostrado relevantes, como faixa etária e grau de escolaridade.

\section{RELAÇÃO ENTRE O USO VARIÁVEL DO IMPERATIVO E AS PROPRIEDADES MORFOSSINTÁTICAS DO PORTUGUÊS BRASILEIRO}

A análise diacrônica de fatores históricos e morfossintáticos contribui para o entendimento desse fenômeno variável, mostrando a relação entre as formas verbais do modo indicativo e do imperativo e o processo de mudança pelo qual passou o sistema pronominal no português brasileiro: do uso predominante do pronome de segunda pessoa do discurso $t u$ até o predomínio do pronome você, em várias regiões do Brasil, como segunda pessoa do discurso e terceira pessoa gramatical.

\subsection{Aspectos históricos}

Historicamente, segundo Faraco (1996, p. 5), a queda do - $t$ final da terceira pessoa do singular do presente do indicativo latino provocou uma homonímia entre essa forma verbal e a forma do imperativo verdadeiro - a segunda pessoa do singular, conforme ilustrado em (18).

Os exemplos em (19) e (20) mostram o uso dessas formas verbais, no modo indicativo e no modo imperativo, respectivamente.

(18) cantat > canta

(19) Ele $f a z$ as atividades.

IND 3S

(20) - Me faz esse favor, doutor. Que belo dia, hein? (VEIGA, 1993, p. 43)

IMP $2 S$ 


\subsection{Aspectos morfológicos}

A análise das mudanças ocorridas no sistema pronominal do português também se mostra fundamental para que se compreenda, por exemplo, a relação entre a variação no uso do imperativo gramatical e a pessoa do discurso. Faraco (1996, p. 53) diz que a mudança no sistema de tratamento no português é uma evidência de que mudanças sociais podem desencadear mudanças lingüísticas e que estas, por sua vez, "desencadeiam uma série de outras mudanças internas". Podemos afirmar que o uso do pronome você, no português brasileiro, em substituição à forma $t u$, para segunda pessoa, interferiu no processo de variação do imperativo gramatical no português brasileiro. Os aspectos descritos a seguir mostram esse processo de mudança.

3.2.1 A gramaticalização/pronominalização de "você", que passa a fazer parte do sistema pronominal como $2^{\mathrm{a}}$ pessoa do discurso e $3^{\mathrm{a}}$ pessoa gramatical, perdendo gradualmente o estatuto de forma de tratamento e assumindo as características de pronome (cf. LOPES \& DUARTE, 2003; ANDRADE, 2004), conforme ilustra (21) e (22). ${ }^{6}$

(21) Vossa Mercê > Você

(22) Você canta.

PRON 2S + V 3S

3.2.2 O uso variável das formas pronominais tu/você para $2^{\mathrm{a}}$ pessoa do discurso (cf. PAREDES et al., 2000; DUARTE \& LOPES, 2003).

(23) Tu cantas. / Você canta.

PRON 2S + V 2S / PRON 2S + V 3S

3.2.3 Uso variável da forma com e sem a marca morfológica de $2^{\mathrm{a}}$ pessoa (24); neutralização da forma verbal de $2^{\mathrm{a}}$ pessoa do singular e de $3^{\mathrm{a}}$ pessoa do singular do modo indicativo (25).

(24) Tu cantas $>$ Tu canta

(25) Tu canta / Você canta / Ele canta

PRON 2S + V 3S / PRON 2S + V 3S/ PRON 3S + V 3S 
Em face dos fenômenos citados, é possível supor que o uso variável das formas do imperativo gramatical no português brasileiro está associado à neutralização das formas verbais de $2^{\mathrm{a}}$ e $3^{\mathrm{a}}$ pessoa em articulação com a neutralização das formas pronominais de $2^{a}$ pessoa do discurso. Até o século XIX, de acordo com estudos de textos escritos, o falante usava, com mais freqüência, o pronome $t u^{7}$ e produzia, predominantemente, o imperativo verdadeiro, ou seja, aquele associado à segunda pessoa do singular (cf. PAREDES SILVA et al., 2000).

No século XX, a forma você passa a predominar como forma pronominal de segunda pessoa, sendo que, nesse contexto, segundo a tradição gramatical, o imperativo é expresso pelas formas associadas ao subjuntivo. Ocorre, porém, no português brasileiro, um uso variável desse modo verbal; o falante não faz essa associação à pessoa do discurso e, motivado por fatores lingüísticos, sociais e históricos, usa o imperativo verdadeiro e a forma substituta em contextos semelhantes, senão idênticos, com um mesmo valor de verdade, a saber, como ato diretivo.

\subsection{Aspectos sintáticos e semânticos que caracterizam a expressão do imperativo gramatical no português brasileiro}

O imperativo gramatical no português brasileiro apresenta algumas características sintáticas e semânticas que lhe asseguram a força ilocutória imperativa. Duas dessas características são descritas a seguir.

\subsubsection{Ausência de sujeito explícito + força (ilocutória) imperativa}

Associada ao contexto discursivo e a aspectos prosódicos e pragmáticos, a realização nula do sujeito na frase pode ser vista como uma forma de codificação gramatical do modo imperativo no português brasileiro, conforme ilustrado em (26). Diferentemente, o sujeito com matriz fonológica (isto é, o sujeito com realização lexical), geralmente, permite uma leitura assertiva, conforme ilustrado em (27).

$\triangle$ FAZ o dever!

(27) Ele / Você faz o dever. ${ }^{8}$ 
Segundo Chierchia (2003, p. 222), a força assertiva equivale a "afirmar que o mundo satisfaz suas condições de verdade". Os imperativos, por sua vez, "podem ser analisados em termos das condições de verdade das proposições que descrevem a execução adequada da ordem que eles expressam". ${ }^{9} \mathrm{Em}$ (27), o objetivo ilocutório é associar o sujeito ao valor expresso pela proposição; já em (26), esse objetivo é o de fazer com que o alocutário realize no futuro a ação verbal da proposição (cf. MATEUS et al., 2003, p. 74)

Mateus et al. (2003, p. 457) observam que o sujeito, nas frases imperativas, designa o ouvinte, conforme exemplo em (26), em que a morfologia desinencial do verbo remete à $2^{\mathrm{a}}$ pessoa do discurso. $\mathrm{O}$ sujeito também pode englobar o locutor, no caso do imperativo na primeira pessoa do plural, como ilustra (28). O constituinte 'Joana', por sua vez, em (29), é interpretado pelas autoras como uma expressão nominal pré-verbal ou pósverbal correferencial com o sujeito, mas realizada como vocativo.

(28) Façamos o dever.

(29) Joana, faz o dever.

Em Cardoso (2004), foram encontrados dados como (30), (31) e (32), coletados em língua escrita, os quais podem ser analisados como atos diretivos. Os constituintes 'você' e o 'senhor' estão sendo analisados em termos da interpretação de Mateus et al. (2003), segundo as quais se trata de "uma expressão nominal pré-verbal" que ocorre em posição periférica e é interpretada como vocativo.

(30) VOCÊ ESPERE aí que eu vou dar uma lição nele - disse Domício e saiu correndo atrás do investigador. (Veiga, 1997)

(31) - Agora VOCÊ FAZ uma garrucha e VIRA caçador - disse eu, apenas para continuar a conversa. (Veiga, 1997)

(32) Não PENSE O SENHOR que eu estou duvidando de sua palavra - concluiu ele. (Veiga, 1997)

No entanto, parece que o estatuto do pronome 'você', em (30) e (31), não é exatamente o mesmo: em (30), é mais evidente a função de vocativo, 
enquanto em (31), identifica-se uma leitura focalizada do pronome. Essa leitura também é observada na forma de tratamento 'o senhor', em (32), que se distingue de (31) pela mudança da ordem em relação ao verbo e pelo uso da forma verbal subjuntiva - provavelmente motivada pela presença da negação. ${ }^{10}$ Percebe-se, também, que essa diferença na interpretação do pronome em (31), em oposição a (30), é compensada pela presença do advérbio agora, que acentua o valor do ato diretivo, trazendo-o para um tempo mais próximo. Além disso, é interessante observar que o uso do indicativo, em (31), aliado ao uso do advérbio agora - com valor de marcador discursivo - poderia sugerir uma leitura de referência indeterminada ao pronome você e conferir à frase uma certa ambigüidade, mas o contexto desfaz essa leitura. Em (30), o uso da forma verbal no subjuntivo assegura a força ilocutória imperativa.

\subsubsection{Uso da forma verbal subjuntiva na oração independente}

O uso da forma verbal do subjuntivo em uma oração independente (matriz) assegura a leitura imperativa da frase, conforme ilustra o exemplo em (33), enquanto na oração encaixada, em (34), por exemplo, a forma do subjuntivo enuncia uma ação incerta que tem relação com o desejo do enunciador (cf. Cunha \& Cintra, 1985, p. 461).

(33) FAÇA o dever.

(34) Espero que Joana faça o dever.

Para Mateus et al. (2003, p. 455), há frases imperativas diretas e indiretas: enquanto as diretas são independentes e o ouvinte é o destinatário do ato proferido (cf. (35) e (36)), as indiretas ocorrem em "domínios de subordinação" e o ouvinte "é o veículo de transmissão" do ato proferido pelo locutor (37).

O exemplo em (37) é um caso de imperativa indireta; note-se, porém, que nesse caso o uso do imperativo verdadeiro, aquele associado ao indicativo, não é possível, como mostra a agramaticalidade de (38). Na oração independente, não haveria restrição ao uso dessa forma verbal, conforme ilustra (36). Para Rivero (1994), uma das propriedades do imperativo verdadeiro é sua realização apenas na oração independente. ${ }^{11}$ 
(36) Joana, FAZ o dever!

(37) Que Joana faça o dever!

(38) * Que Joana faz o dever!

No português brasileiro, a forma subjuntiva na oração independente (forma surrogate, nos termos de Rivero, 1994) é a que assegura a leitura imperativa da frase. $\mathrm{O}$ uso da forma associada ao indicativo (imperativo verdadeiro, nos termos de Rivero, op. cit.), em alguns contextos, pode precisar de âncoras discursivas (vocativo, prosódia, advérbio) que forneçam evidências de que se trata de uma frase imperativa e não de uma frase assertiva, com sujeito nulo, conforme exemplo em (39), (cf. também SCHERRE, 2002, 2004; SCHERRE et alii, 2005).

(39) (Ela/ Joana) FAZ o dever.

A possibilidade de perda da leitura imperativa em frases construídas com a forma associada ao indicativo pode ser um indício da perda gradual da oposição morfológica entre o imperativo verdadeiro e a forma substituta. Levantamos a hipótese de que a necessidade de apoio discursivo se dá em razão do enfraquecimento dos traços do imperativo verdadeiro, que apresenta, no português brasileiro, um traço (-) marcado, em termos de freqüência e complexidade cognitiva, nos termos de Givón (1995). ${ }^{12} \mathrm{O}$ subjuntivo, por sua vez, apresenta características de categoria (+) marcada e, quando está na oração independente, não apresenta dependência do contexto (cf. CÂMARA JR., 1979, p. 133), assegurando a força ilocutória imperativa. A reanálise do você, que passa a integrar o sistema pronominal do português brasileiro como $2^{\mathrm{a}}$ pessoa do discurso, e a neutralização das formas verbais de $2^{\mathrm{a}}$ e $3^{\mathrm{a}}$ pessoa também são fatores que podem ter contribuído para esse enfraquecimento da morfologia do imperativo verdadeiro.

Além dos aspectos sintáticos citados - em particular a correlação com a realização nula do sujeito e com a ocorrência em orações independentes (ou orações raiz) -, outro aspecto relevante é a relação entre a expressão do imperativo gramatical e a sintaxe da negação. Essa relação é particularmente interessante no caso do português brasileiro, que apresenta características singulares na sintaxe de negação, quando comparado a outras línguas românicas, conforme será demonstrado na seção a seguir. 


\section{RELAÇÃO ENTRE A SINTAXE DA NEGAÇÃO E A EXPRESSÃO GRAMATICAL DO IMPERATIVO NO PB}

Segundo Zanuttini (2005), há uma correlação entre as estratégias de negação das línguas e a possibilidade de negar o imperativo verdadeiro. Nessa análise, a autora parte do agrupamento das línguas românicas e de alguns dialetos românicos, de acordo com suas estratégias de negação. Sendo assim, identifica línguas de negação pré-verbal, como o espanhol, o italiano, o português europeu; línguas de negação pós-verbal, como as línguas do norte da Itália; e línguas de dupla negação, como ocorre no francês padrão.

\subsection{Caracterização das línguas românicas de acordo com as estratégias de negação das orações}

Para Zanuttini (2005), o uso de uma das estratégias de negação em uma dada língua correlaciona-se com a presença/ausência de restrições na distribuição de quantificadores de negação.

- Línguas com marcas de negação pré-verbal não negam imperativo verdadeiro (cf. também RIVERO, 1994).

(40) a. *Non telefona! (imperativo verdadeiro) (italiano)

b. Non telefonate! (imperativo substituto)

- Línguas com marcas de negação pós-verbal negam o imperativo verdadeiro.

(41) a. Parla! (imperativo verdadeiro) (piemontês)

b. Parla nen! (imperativo verdadeiro)

Conclui-se, assim, que a forma verdadeira não pode ser dominada sintaticamente pela negação, sendo necessário acionar a forma substituta; se a negação é pós-verbal, não há restrição à ocorrência do imperativo verdadeiro. Para Rivero (1994, p. 95), o imperativo verdadeiro e a marca de negação estão em distribuição complementar, porque ocorrem na mesma posição na estrutura oracional. Segundo a autora, as formas substitutas exibem a mesma ordem de palavras que o imperativo verdadeiro em presença de clítico, mas contrastam com o imperativo verdadeiro na presença de negação pré-verbal, visto que esta 
bloqueia o movimento do verbo, impedindo que o imperativo verdadeiro seja negado (cf. também RIVERO \& TERZI, 1995, p. 307).

\subsection{O imperativo negativo e a sintaxe de negação no PB}

No português brasileiro, a posição canônica da negação é à esquerda do verbo, porém há registros que evidenciam as três estratégias de negação, como mostram os exemplos retirados de Ramos (2002, p. 155): negação préverbal, em (42); pós-verbal, em (43) e dupla negação, em (44) (cf. também ALKMIM, 2002; FURTADO DACUNHA, 2001).

(42) E se eu não sou formada hoje (E28)

(43) Acredito não (E30)

(44) Que eu não concordava com aquilo não (E09)

O fato de o português brasileiro caracterizar-se como uma língua, predominantemente, de negação pré-verba ${ }^{13}$ não impede a negação do imperativo verdadeiro, tanto na língua escrita (45) como na falada (46). Contudo, vários estudos que investigam o uso variável do imperativo gramatical mostram que há uma tendência ao favorecimento do uso da forma substituta em frases imperativas negativas, como em (47) (cf. SCHERRE, 2001; SAMPAIO, 2001; CARDOSO, 2004).

(45) Não ATRASA a boiada. (Veiga, 1994, p. 152)

(46) Não ENTRA no mar! (42F)

(47) Não DEIXE o jasmineiro da varanda do quarto morrer. (Veiga, 1995, p. 24)

Os dados da tabela 1 mostram o percentual de uso do imperativo verdadeiro em frases imperativas negativas, em contexto de pronome você, de acordo com os resultados de Scherre et al. (1998), na análise de discurso falado; Scherre (2001), na análise de dados de histórias em quadrinhos da Turma da Mônica, publicadas em 1998 e 1999; de Sampaio (2001), na análise de dados de língua falada em Salvador e de Cardoso (2004), com dados de língua escrita de José J. Veiga. 
TABELA 1

Freqüência de uso do imperativo na forma indicativa (imperativo verdadeiro) em função da polaridade das estruturas

\begin{tabular}{c|c|c|c|c}
\hline Fatores & $\begin{array}{c}\text { Discurso falado } \\
\text { (Scherre } \text { et al., } \\
\text { 1998) }\end{array}$ & $\begin{array}{c}\text { Histórias em } \\
\text { quadrinhos } \\
\text { (Scherre, 2001) }\end{array}$ & $\begin{array}{c}\text { Língua falada } \\
\text { de Salvador } \\
\text { (Sampaio, 2001) }\end{array}$ & $\begin{array}{c}\text { Textos escritos } \\
\text { de José J. Veiga } \\
\text { (Cardoso, 2004) }\end{array}$ \\
\hline $\begin{array}{c}\text { Frases imperativas } \\
\text { afirmativas }\end{array}$ & $82 \%$ & $61 \%$ & $29 \%$ & $25 \%$ \\
\hline $\begin{array}{c}\text { Frases imperativas } \\
\text { negativas }\end{array}$ & $66 \%$ & $25 \%$ & $20 \%$ & $8 \%$ \\
\hline
\end{tabular}

Em todas as amostras, o percentual de uso do imperativo verdadeiro é menor quando se trata de frases imperativas negativas, ou seja, há uma tendência a negar menos o imperativo verdadeiro. Cardoso (2004) separou as estruturas imperativas negativas de acordo com as três estratégias de negação e obteve os seguintes resultados.

TABELA 2

Uso do imperativo na forma indicativa em função da posição da partícula negativa

\begin{tabular}{c|c|c}
\hline Fatores & Indicativo/Total & $\begin{array}{c}\text { Porcentagem da } \\
\text { forma indicativa }\end{array}$ \\
\hline Negação pré-verbal & $7 / 87$ & $8 \%$ \\
\hline Negação pós-verbal & $18 / 30$ & $60 \%$ \\
\hline Dupla negação & $4 / 6$ & $67 \%$ \\
\hline
\end{tabular}

Os resultados percentuais mostram que a negação pós-verbal e a dupla negação tendem a favorecer o uso do imperativo verdadeiro, como ilustrado em (48) e (49), mas também ocorre o uso de imperativo substituto, como ilustrado em (50) e (51), ainda que em percentual significativamente menor. Cardoso (2004) analisou essa polaridade nos resultados com frases imperativas negativas na linha da mitigação: "o uso da estrutura V+NEG e V+NEG+V 
produz, pelo menos, dois efeitos: (i) minimiza o ato de fala refutativo; (ii) aumenta a ocorrência de formas indicativas para o imperativo."

(48) - FECHA não, Amâncio! (Veiga, 1997, p. 43)

(49) - Josia, Josia. Não MORRE não, Josia. (Veiga, 1994, p. 143)

(50) - FIQUE assim não, Gemi. Ora essa! (Veiga, 1997, p. 47)

(51) - Não LIGUE para mim não, Za. (Veiga, 1997, p. 111)

Embora a mitigação dos atos de fala seja um fator determinante nesse processo de variação, evidencia-se que esse não é um fator determinístico, ou seja, não há um caso de distribuição complementar que marque os contextos de uso de uma ou outra forma.

A tabela 2 mostra que a maioria das estruturas apresenta o NÃO na posição pré-verbal. Essa posição marca a negação de forma mais intensa no modo imperativo. É uma negação não-marcada por elemento de reforço. Já a dupla negação evidencia a intenção do autor de reforçar o que está sendo negado, como em (52) e (53).

(52) NÃO vai a pé NÃO - disse ele. (VEIGA, 1994)

(53) Josia, Josia. NÃO morre NÃO, Josia. (VEIGA ,1994)

A negação pós-verbal aponta para uma ordem marcada por um pedido com traço de (+) humildade ou por uma ordem (-) rude, como em (54) e (55).

(54) Eu espero. Manda chamar NÃO - disse o homem. (Veiga, 1994)

(55) Exagero. Servicinhos à-toa. Um puxado. Um chiqueiro. Remendos. Dê ouvido a conversas NÃO. (Veiga, 1997)

Os dados apresentados demonstram que o português brasileiro não apresenta exatamente o mesmo padrão de distribuição das formas do imperativo em função do tipo de negação, descrito em Zanuttini (2005) para línguas românicas, em que se postula uma relação categórica entre a possibilidade de negar a forma do imperativo verdadeiro e a posição da negação, que deve ser pós-verbal; ou inversamente, em que se verifica a impossibilidade de negação do imperativo verdadeiro em línguas com negação 
pré-verbal. Considerando, contudo, o encaixamento lingüístico da variação, em que a negação pós-verbal e a dupla negação favorecem o uso da forma do imperativo verdadeiro, confirma-se, em termos de tendência, a correlação entre a posição da negação e a distribuição das formas do imperativo, tal como formulada por Zanuttini.

O fato de, no português brasileiro, a dupla negação se alinhar com a negação pós-verbal (e não com a pré-verbal), no que se refere à ocorrência da forma do imperativo verdadeiro, sugere que o fator determinante é a possibilidade de a negação ocorrer na posição pós-verbal - nesse sentido, pode-se considerar que a dupla negação no português brasileiro apresenta propriedades semelhantes à dupla negação no francês (ne...pas), em que se constata que o elemento dominante é a segunda posição.

Outra evidência desse domínio é a possibilidade de o não à esquerda do verbo, ilustrado em (52) e (53), ser realizado como num em alguns dialetos. Segundo Ramos (2002), esse item fonologicamente mais fraco pode ser reforçado por outra forma plena, no caso, o não pós-verbal.

\section{CONSIDERAÇÕES FINAIS}

Este estudo examinou propriedades da expressão do imperativo gramatical no português brasileiro, em diálogos da fala e da escrita, considerando aspectos morfossintáticos e semânticos e a correlação entre o uso variável das formas do imperativo verdadeiro e do imperativo substituto e a sintaxe da negação.

Constata-se que, no português brasileiro, o uso do modo imperativo gramatical varia entre as formas do imperativo verdadeiro e do imperativo substituto, tanto para língua escrita como para língua falada. Fatores lingüísticos e sociais interferem nesse processo de variação, sendo que cada região do país exibe percentuais diferentes, de acordo com as pesquisas citadas.

A posição da negação na frase é um dos fatores que favorecem o uso variável desse modo verbal. O português brasileiro é uma língua que apresenta as três estratégias de negação e os fatos mostram que essa posição não impede o uso variável do verbo nas frases imperativas, embora haja tendência em direção a uma ou outra variante: a negação pré-verbal favorece a forma substituta enquanto a negação pós-verbal e a dupla negação favorecem o imperativo verdadeiro. 
Para explicar a possibilidade de licenciar a negação do imperativo verdadeiro, levanta-se a hipótese de que o português brasileiro não tenha essa característica, no sentido de forma morfologicamente marcada para o modo imperativo. A perda de morfologia própria pode ter ocorrido basicamente em função de dois fatores: a inserção do pronome de tratamento você no sistema pronominal brasileiro, como pronome pessoal de segunda pessoa, e a neutralização das formas verbais da terceira pessoa do singular do indicativo e da segunda pessoa do modo imperativo.

Podemos também associar a provável perda da morfologia do modo imperativo a um enfraquecimento gradual dos traços do imperativo verdadeiro - força ilocutória imperativa - a partir do século XIX, acentuando-se no século XX, com o movimento modernista (cf. PAREDES SILVA, 2000). O traço (+) freqüente do modo indicativo associado à neutralização das formas verbais $\mathrm{e}$ pronominais teria favorecido esse enfraquecimento. Uma evidência dessa mudança na força do traço semântico do verbo é a constatação de que o imperativo verdadeiro, na escrita, sem âncora discursiva, nos termos de Scherre (2006), nem sempre assegura leitura imperativa à frase; outras vezes, pode gerar ambigüidade, conforme foi apresentado nas seções 3.3.1 e 3.3.2. Pelo menos dois seriam os efeitos desse processo de mudança: o aumento do percentual de uso da forma associada ao indicativo em frases imperativas em algumas regiões do Brasil (Sul, Centro-Oeste e Sudeste, especificamente); e o licenciamento da negação da forma associada ao indicativo.

Devemos, contudo, avaliar essa hipótese da perda da morfologia do imperativo verdadeiro considerando também os resultados obtidos com as frases imperativas negativas. Os percentuais observados até agora mostram que a oposição morfológica persiste, visto que a negação pré-verbal favorece o uso do imperativo substituto e a negação pós-verbal e a dupla negação favorecem o uso do imperativo verdadeiro.

A continuidade da pesquisa visa à ampliação do entendimento sobre a correlação entre a negação e o modo imperativo, bem como à análise de outros traços - sintáticos, semânticos, discursivos e prosódicos - que interferem na relação entre a posição da negação e o uso variável das formas do imperativo gramatical. 


\section{NOTAS}

* Este trabalho foi desenvolvido no âmbito da Pós-Graduação em Lingüística da Universidade de Brasília, sob a orientação da Profa. Dra. Marta Scherre e coorientação da Profa. Dra. Heloisa Salles, às quais gostaria de agradecer pelas discussões e pelas valorosas sugestões.

${ }^{1}$ Com base nas idéias de Searle (1969), entendemos o ato ilocutório como aquele realizado quando o falante afirma, ordena, deseja ou faz uma crítica; o locutor e o alocutário são os interlocutores envolvidos na comunicação: o primeiro é o responsável pelo enunciado; o segundo representa a pessoa a quem a mensagem é dirigida.

${ }^{2}$ As autoras também distinguem essas línguas em função da posição do clítico: em línguas de classe I, no imperativo, o clítico vem em posição enclítica (depois do verbo); no indicativo e no subjuntivo, o clítico vem em posição proclítica (antes do verbo). Já nas línguas de classe II, o clítico vem sempre em segunda posição, depois do verbo, em função de uma exigência prosódica da língua.

${ }^{3}$ Consideramos aqui a seguinte associação: o imperativo verdadeiro na terminologia de Rivero (1994) corresponde, sincronicamente, no PB, às formas associadas ao modo indicativo; o imperativo surrogate corresponde às formas associadas ao modo subjuntivo.

${ }^{4}$ Estabelecemos aqui a diferença entre pessoa do discurso e pessoa gramatical; o pronome você está sendo designado como pronome de $2^{\text {a }}$ pessoa do discurso que controla a concordância do verbo na $3^{\mathrm{a}}$ pessoa gramatical.

${ }^{5}$ Os dados fazem parte de um corpus que está sendo formado com falantes de Fortaleza. As indicações entre parênteses referem-se a informações sobre o informante: faixa etária e gênero.

${ }^{6}$ Em relação ao processo de gramaticalização da forma 'você' no sistema pronominal do PB, além da difusão/ frequiência da forma e do esvaziamento de traços lexicais codificadores de assimetrias de tratamento entre os interlocutores, aspectos formais, como a redução fonológica e a distribuição sintática, têm sido mencionados para justificar esse processo (para uma revisão dos argumentos e um estudo das formas variantes do pronome 'você' no PB, veja-se Andrade (2004), e referências ali citadas).

${ }^{7}$ Segundo Lopes \& Duarte (2003), o percentual de uso do pronome tu chegou a 90\% na primeira metade do século XIX; no fim desse século, sofre um declínio, 
voltando ao índice do século XVIII, de $60 \%$. Nesses períodos, o pronome você mantém o percentual médio de $10 \%$ e, a partir da segunda metade do XIX, polariza-se com $t u$.

${ }^{8}$ É interessante notar que a construção com sujeito expresso realizado pela forma pronominal 'você' produz um resultado ambíguo em relação a uma leitura assertiva ou diretiva.

${ }^{9} \mathrm{O}$ imperativo, por ser ato diretivo, pode assumir valor de ordem, conselho, súplica ou pedido.

${ }^{10}$ A negação é um dos fatores motivadores da variação das formas verbais no modo imperativo. Essa questão será discutida na seção 4.

${ }^{11}$ Segundo a autora, as outras duas propriedades do imperativo verdadeiro são: o imperativo verdadeiro não pode ser negado e o clítico sempre segue essa forma verbal (cf. também Scherre et al, 2005).

${ }^{12}$ Givón (1995, p. 28) define três critérios usados para distinguir estruturas mais marcadas das menos marcadas: complexidade estrutural - categorias marcadas tendem a ter uma estrutura mais complexa ou maior; distribuição da freqüência - categorias mais marcadas são as menos freqüentes e cognitivamente mais salientes; complexidade cognitiva - categorias marcadas tendem a ter estruturas cognitivas mais complexas. Considera-se para a análise o esforço mental, a atenção despendida e o tempo de processamento.

${ }^{13}$ Furtado da Cunha (2001), em sua pesquisa com dados de língua falada e escrita na cidade de Natal, analisou 1649 orações negativas que exibem a seguinte distribuição de acordo com as estratégias de negação: i. língua falada - 1298 dados com estruturas de negação pré-verbal; 09 de negação pós-verbal e 158 de dupla negação; ii. Língua escrita - 184 dados de negação pré-verbal. 


\section{REFERÊNCIAS BIBLIOGRÁFICAS}

ABREU, Renata Sousa P. de. Estudo da variação do modo imperativo em obras de Jorge Amado. Brasília, Universidade de Brasília. 2003. (Inédito.)

ALKMIM, Mônica G. R. Negativa pré- e pós-verbal: implementação e transição. In: Dialeto mineiro e outras falas. Belo Horizonte: FALE/UFMG, 2002.

ALVES, Gilson Chicon. A influência da simplificação da conjugação verbal da construção do imperativo. In: HORA, Dermeval da (Org.). Estudos Sociolingüísticos - perfil de uma comunidade. João Pessoa: UFPB. 2004.

ANDRADE, Adriana Lilia V. S. A variação entre você, cê e ocê no português brasileiro falado. 2004. Dissertação (Mestrado em Lingüística) - Universidade de Brasília, Brasília.

BECHARA, Evanildo. Moderna gramática portuguesa. Rio de Janeiro: Lucerna, 1999.

CAMARA JR., Joaquim Mattoso. História e Estrutura da Língua Portuguesa. Rio de Janeiro: Padrão, 1979.

CARDOSO. Daisy Bárbara Borges.Variação no uso do modo imperativo: análise de dados em textos de José J. Veiga. 2004. Dissertação (Mestrado em Lingüística) - Universidade de Brasília, Brasília.

CHIERCHIA, Gennaro. Semântica. Trad. Luis Arthur Pagani, Lígia Negri, Rodolfo Ilari. Campinas, SP: Editora da UNICAMP; Londrina, Pr: EDUEL, 2003.

CUNHA, Celso; CINTRA, Luís F. Lindley. Nova Gramática do Português Contemporâneo. Rio de Janeiro: Nova Fronteira, 1985.

FARACO, Carlos Alberto. O tratamento você em português - uma abordagem histórica. Fragmenta. Curitiba: Editora da Universidade Federal do Paraná (UFPR), n.13, p. 51-82, 1996.

FARACO, Carlos A. Considerações sobre a sentença imperativa no português do Brasil. DELTA 2 (1): p. 1-15, 1986.

FURTADO DA CUNHA, M. A. O modelo das motivações competidoras no domínio funcional da negação. DELTA: Documentação de Estudos em Lingüística Teórica e Aplicada, São Paulo, v. 17, n. 1, p. 1-30, 2001. 
GIVÓN, T. Functionalism and grammar. Philadelphia, USA: John Benjamins Publishing Company, 1995.

JESUS, Étel Teixeira. O uso do imperativo na novela Senhora do destino: estereótipo ou identidade? In: $57^{\mathrm{a}}$ Reunião Anual da SBPC, 2005, Fortaleza. Livro de Resumos.

LOPES, C. R. S.; DUARTE, M. E. L. De Vossa Mercê a Você: análise da pronominalização de nominais em peças brasileiras e portuguesas setecentistas e oitocentistas. In: BRANDÃO, Sílvia; MOTA, M. Antónia. (Org.). Análise Constrastiva de Variedades do Português: primeiros estudos. Rio de Janeiro, 2003. p. 61-78.

MATEUS, Maria Helena Mira et al. Gramática da língua portuguesa. Lisboa: Caminho, 2003.

MATTOS, Ana; WICKERT, Andréa. A expressão do imperativo na obra de Chico Buarque. Brasília: UnB, 2002. (Inédito.)

PAREDES SILVA, Vera Lúcia et al. Variação na $2^{a}$ pessoa: o pronome sujeito e a forma do imperativo. Niterói, n. 9, p.115-123, 2000.

RAMOS, Jânia. O uso das formas Você, Ocê, Cê no dialeto mineiro. In: HORA, Dermeval (Org.). Diversidade Lingüística no Brasil. João Pessoa: Martins, 1997. p. 43-60.

RAMOS, Jânia. A alternância entre não e num no dialeto mineiro: um caso de mudança lingüística. In: COHEN, M. A.; RAMOS, J. Dialeto mineiro e outras falas. Belo Horizonte: FALE/UFMG, 2002. p. 155-167.

RIVERO, Maria-Luisa. Negation, Imperatives and Wackernagel effects. Rivista di Linguistica 6.1, p. 39-66, 1994.

RIVERO, María Luisa; TERZI, Arhonto. Imperatives, V-movement and logical mood. Journal of Linguistics 31(2): 301-332, 1995.

SAMPAIO, Dilcélia Almeida. Modo imperativo: sua manifestação/expressão no português contemporâneo. 2001. Dissertação (Mestrado) - UFBA, Salvador.

SCHERRE. Maria Marta Pereira et al. Phonic parallelism: evidence from the imperative in Brazilian Portuguese. Papers in Sociolinguistics. NWAVE-26 à l'Université Laval (Québec): Nota Bene. 1998. p. 63-72. 
SCHERRE, Maria Marta Pereira et al. Restrições sintáticas e fonológicas na expressão variável do imperativo no português do Brasil. II Congresso Nacional da ABRALIN e XIV Instituto Lingüístico. Florianópolis: Taciro - Produção de Cds Multimídia, 2000. p. 1333-1347.

SCHERRE, Maria Marta Pereira; BRASIL, Eduardo e. Norma e uso na variação do imperativo em revistas em quadrinhos da Turma da Mônica. I Encontro Nacional do GELCO (Grupo de Estudos de Linguagem do Centro-Oeste). Campo Grande: UFMS. 2001.

SCHERRE, Maria Marta Pereira. A norma do imperativo e o imperativo da norma - Uma reflexão sociolingüística sobre o conceito de erro. In: BAGNO, Marcos (Org.). Lingüística da Norma. Loyola, São Paulo, 2002. p. 217-265.

SCHERRE, Maria Marta Pereira. Norma e uso - o imperativo no português brasileiro. In: DIETRICH, Wolf; NOLL, Volker. (Org.). O Português do Brasil - Perspectivas da pesquisa atual. (Lingǘstica luso-brasileira, Vervuert / Iberoamericana, 2004. p. 231-260.

SCHERRE, Maria Marta Pereira. O imperativo gramatical no português brasileiro: reflexo de mudança lingüística na escrita de revistas em quadrinhos. 2006. A sair em livro organizado por Sebastião Josué Votre e Cláudia Roncarati. Livro em homenagem a Anthony Julius Naro.

SCHERRE, Maria Marta Pereira; CARDOSO, Daisy Bárbara; LUNGUINHO, Marcus Vinicius da Silva. O imperativo gramatical no português brasileiro: uma discussão translingüística. In: IV CONGRESSO INTERNACIONAL DA ABRALIN, 2005, Brasília. ABRALIN 2005 - Livro de Resumos, 17-19/02/ 2005, p. 63. Brasília: ABRALIN/UnB, 2005.

SEARLE, J. Speech acts. Cambridge: Cambridge University Press, 1969.

ZANUTTINI, Raffaela. Syntactic Variation and Study of Dialects. NWAV, 20 out. 2005. (handout) 